\title{
Updates in ASIA Examination: Upper Extremity Motor Examination
}

\author{
Belgin ERHAN ${ }^{1,2}$, Berrin GÜNDÜZ \\ 'Istanbul Physical Medicine Rehabilitation Training and Research Hospital, Istanbul, Turkey \\ ${ }^{2}$ Istanbul Aydın University, Health Services Vocational School of Higher Education, Istanbul, Turkey
}

\begin{abstract}
The most common method used in the clinical assesment and classification of spinal cord injury patients is "International Standards for Neurological Classification of Spinal Cord Injury (ISNCSCI)" developed by the American Spinal Cord Association (ASIA) and approved by the International Spinal Cord Society (ISCOS). In clinical trials, performing a standardized physical examination is useful for comparing data and to build a standard terminology among professionals dealing with the disease. These standards were revised in 2011 and updated in 2013 by ASIA. In this article, motor evaluation of the upper extremities is discussed, according to the 2011 revision and 2013 update.

Keywords: Spinal cord injury, ASIA evaluation, upper extremity motor examination, ASIA 2011 revision
\end{abstract}

\section{Introduction}

One of the important stages of spinal cord injury $(\mathrm{SCl})$ rehabilitation is the comprehensive evaluation of patients (1). The most sensitive way of evaluating patients who sustained a $\mathrm{SCl}$ is to perform a standardized neurological examination (2). The most common standardized clinical evaluation and classification method recently used worldwide is the International Standards for Neurological Classification of Spinal Cord Injury (ISNCSCI), which was developed by the American Spinal Injury Association (ASIA) and approved by the International Spinal Cord Society (ISCOS) $(3,4)$.

The standards that were developed constitute a common language for professionals interested in the disease and also provide standardization for intercenter data comparison (2).

Neurological examination standards were revised by ASIA in 2011 (3,5). The examination form was then updated in 2013 (6). In this article, the motor examination of the upper extremi- ties is discussed in detail in accordance with the 2011 revision and 2013 update.

In the motor examination, 10 myotome pairs [5 pairs in the upper extremities (C5-T1) and 5 in the lower extremities (L2-S1)] and corresponding key muscle functions are evaluated (Table 1). It is recommended that each key muscle function should be assessed in the rostral-caudal line and in the supine position and by stabilizing the muscle $(3,7)$. Inappropriate positioning and stabilization can cause other muscles to be evaluated by mistake. The muscles chosen as key muscles have common features including being innervated from a specified segment, being innervated from at least two spinal segments, having functional significance, and being able to be easily reached and isolated in the supine position (3).

The positioning of these key muscles during evaluation and the points to which attention must be paid are explained in the motor evaluation training module of the InSTeP program, which can be accessed on the websites of ASIA and ISCOS in detail $(8,9)$. 
A 6-point scale is used in the assessment of muscle strength (Table 2). In motor evaluation in international standards, the use of plus and minus values is not recommended (3). If more than half of the range of joint motions (ROM) can be performed in joints with contracture, the muscle is evaluated to be normal (0-5); if not, the muscle is recorded as not testable (NT) $(3,5)$. In the presence of spasticity, if spasticity prevents the muscle from being properly positioned and causes uncontrollable clonic activity, muscle strength is recorded as NT (InSTeP) (3-5,8).

In myotomes where manual muscle testing cannot be clinically performed, motor evaluation is conducted using sensory levels. At the C1-C4, T2-L1, and S2-S5 levels, the motor level is accepted to be the same as the sensory level, provided that key muscles are normal (3).

In ISNCSCI revised by ASIA in 2011, some positions during the evaluation of grades of muscle strength $4 / 5$ and 5/5 are described (Table 3 ). It is recommended to comply with these special positions during evaluation.

The motor evaluation of the upper extremities begins with the assessment of grade 3 muscle strength. If the patient can achieve grade 3 muscle strength, the evaluation is continued with grades 3 and 4 . However, if the patient cannot achieve grade 3 muscle strength, the evaluation continues with grades 2,1 , or $0(3,7-9)$.

\section{C5 Elbow Flexors-Biceps Brachii and Brachialis}

\section{Muscle strength grade $3 / 5$}

The wrist of the patient is supported when the shoulder is in neutral rotation, flexion/extension, and adduction; the elbow is fully extended; the forearm is in full supination; and the wrist is in neutral flexion/extension. The patient is instructed to "bend your elbow and try to bring your hand to your nose". If the patient completes elbow flexion through the full range of motion, the grade of muscle strength is 3/5 (Figure 1).

\section{Muscle strength grades 4/5 and 5/5}

The patient is stabilized from the anterior shoulder when the shoulder is in neutral rotation, flexion/extension, and adduction; the elbow is in $90^{\circ}$ of flexion; and the forearm is fully supinated. The volar aspect of the wrist is grasped, and a force is applied in the direction of elbow extension. The patient attempts to hold the elbow at $90^{\circ}$ while resisting the force applied by the examiner. If the patient shows full resistance to the force, the grade of muscle strength 5, whereas if the patient shows partial resistance, the grade is 4 (Figure 2 ).

\section{Muscle strength grade 2/5}

The forearm is placed above the abdomen, just below the umbilicus, when the shoulder is in internal rotation and adduction. The arm is supported with the elbow in $30^{\circ}$ of flexion and the forearm and wrist in neutral supination/pronation. The patient is instructed to "bend your elbow and try to bring your hand to your nose". If the patient can perform the movement through a full range of motion, the grade of muscle strength is $2 / 5$.

\section{Muscle strength grades $0 / 5$ and $1 / 5$}

The patient is in the grade 2 position with the shoulder in internal rotation and adduction. When the elbow is in $30^{\circ}$ of flex-

Table 1. The key muscles used in evaluating the muscle strength of the upper extremities and the related roots and segments of the spinal cord

C5- Elbow flexors (biceps, brachialis)

C6- Wrist extensors (extensor carpi radialis longus and extensor carpi radialis brevis)

C7- Elbow extensors (triceps)

C8- Long finger flexors, middle finger (flexor digitorum profundus)

T1- Finger abductors, small finger (abductor digiti minimi)

\section{Table 2. Muscle function rating (3)}

0: Total paralysis

1: Palpable or visible contraction

2: Active movement, full range of joint motion with the elimination of gravity (ROM)

3: Active movement, full ROM against gravity

4: Active movement, full ROM against gravity, and moderate resistance in a muscle-specific position

5: (Normal) Active movement, full ROM against gravity, and full resistance of muscle in a specific position that is expected from a healthy individual

5*: (Normal) Active movement, full ROM against gravity, and adequate resistance that will be considered normal in the absence of identified inhibitory factors (pain, disuse)

NT: Not testable (due to, for instance, immobilization, severe pain that can prevent the grading of the patient, extremity amputation, or $>50 \%$ contracture of ROM)

Table 3. Myotome that is evaluated, key muscle, and positions recommended while evaluating muscle strength grades $4 / 5$ and $5 / 5(3,8,9)$

\begin{tabular}{|c|c|c|}
\hline Myotome & Key muscle & Positions recommended while evaluating muscle strength grades $4 / 5$ and $5 / 5$ \\
\hline C5 & Elbow flexors (biceps, brachialis) & The elbow is in $90^{\circ}$ of flexion, the arm is by the patient, and the forearm is in supination \\
\hline C6 & $\begin{array}{l}\text { Wrist extensors (extensor carpi radialis } \\
\text { longus and extensor carpi radialis brevis) }\end{array}$ & The wrist is in full extension \\
\hline C7 & Elbow extensors (triceps) & $\begin{array}{l}\text { The shoulder is in neutral rotation, adduction, and } 90^{\circ} \text { of flexion; and the } \\
\text { elbow is in } 45^{\circ} \text { of flexion }\end{array}$ \\
\hline $\mathrm{C} 8$ & $\begin{array}{l}\text { Finger flexors, middle finger } \\
\text { (flexor digitorum profundus) }\end{array}$ & $\begin{array}{l}\text { Distal phalanx in full flexion while proximal finger joints are stabilized in } \\
\text { extension }\end{array}$ \\
\hline
\end{tabular}


ion and the palm, forearm, and wrist are above the abdomen and in neutral pronation/supination, the examiner supports the forearm of the patient with one hand. While the other hand palpates the biceps tendon in the cubital fossa or the belly of the biceps brachii, the patient is instructed to "bend your elbow and try to bring your hand to your nose". The patient attempts to perform elbow flexion through the range of motion (Figure 3).

\section{C6 Wrist Extensors-Extensor Carpi Radialis Lon- gus and Extensor Carpi Radialis Brevis}

\section{Muscle strength grade $3 / 5$}

When the shoulder is in neutral rotation, adduction, and flexion/extension; the elbow is fully extended; the forearm is in full pronation; and the wrist is in flexion; the forearm is supported from the distal forearm, and the patient is instructed to "bend your wrist upwards and lift your fingers toward the ceiling". If the patient completes the range of joint motion, the grade of muscle strength is $3 / 5$ (Figure 4).

\section{Muscle strength grades $4 / 5$ and 5/5}

The position of the patient is the same as the previous position, except that the wrist is in full extension (with the grade of muscle strength 3/5). The wrist is held and stabilized. A force is applied across the metacarpals toward flexion and (because radial wrist extensors are tested) ulnar deviation. The patient is instructed to "lift your wrist up and hold, and don't let me push it down". The patient tries to resist the force applied by the examiner and attempts to maintain the wrist in full extension. If the patient shows full resistance to the force, the grade of muscle strength is 5 . If the patient shows partial resistance to the force, the grade of muscle strength is 4 (Figure 5).

\section{Muscle strength grades $0 / 5,1 / 5$, and 2/5}

The arm of the patient is in the supine position on the examination table. The forearm is supported, and the patient is asked to bend the wrist backwards into extension when the shoulder is in neutral flexion/extension, neutral rotation, and adduction; the elbow is fully extended; the forearm is in neutral supination/ pronation; and the wrist is fully extended (or alternatively, when the arm is above the abdomen; the shoulder is in slight flexion, internal rotation, and adduction; the elbow is flexed to $90^{\circ}$; the forearm is in full supination; and the wrist is in flexion). If the

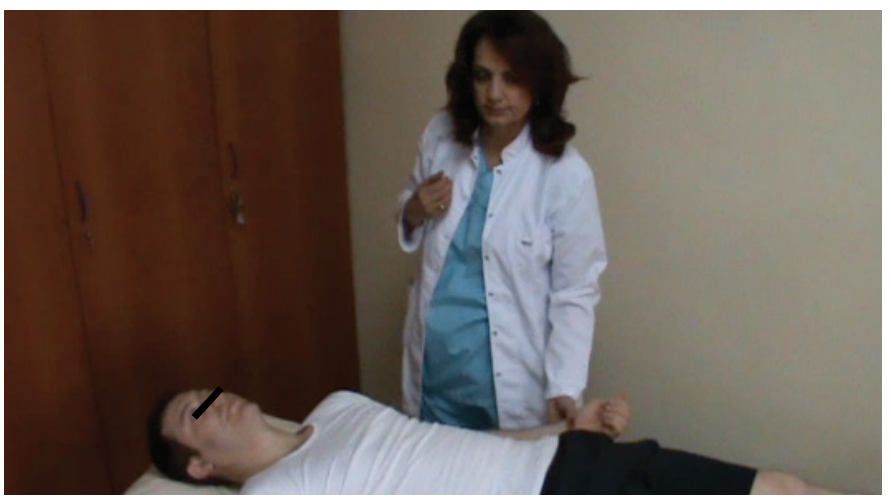

Figure 1. Evaluation position of muscle strength grade $3 / 5$ in elbow flexion patient completes the range of motion in extension, the grade of muscle strength is $2 / 5$. If not, to determine trace function, the radial wrist extensors are palpated from the side proximal to the wrist, and the radial aspect of the forearm or the muscle belly is observed. If trace motion is palpated or there is visible contraction, the grade of muscle strength is $1 / 5$. If no motion is felt or observed, the grade of muscle strength is $0 / 5$ (Figure 6).

Note: If the position and stabilization of the forearm are not correct, the motion of the wrist extensors can be mimicked by the forearm supinators with the help of gravity.

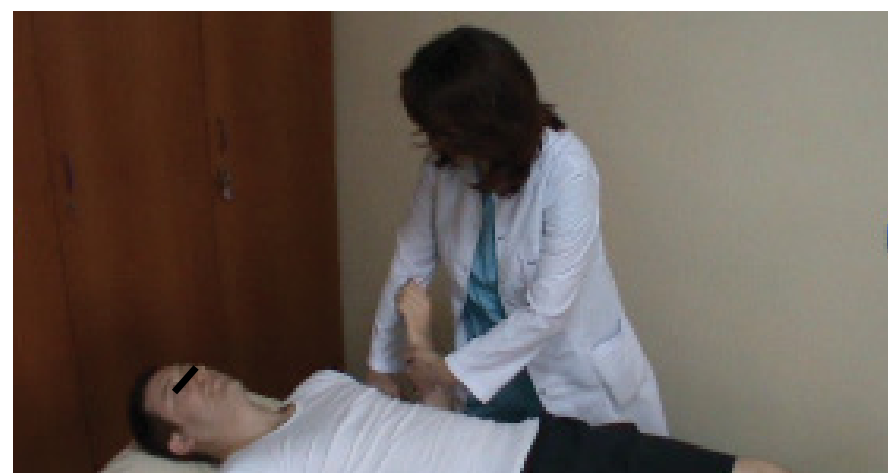

Figure 2. Evaluation position of muscle strength grades $4 / 5$ and $5 / 5$ in elbow flexion

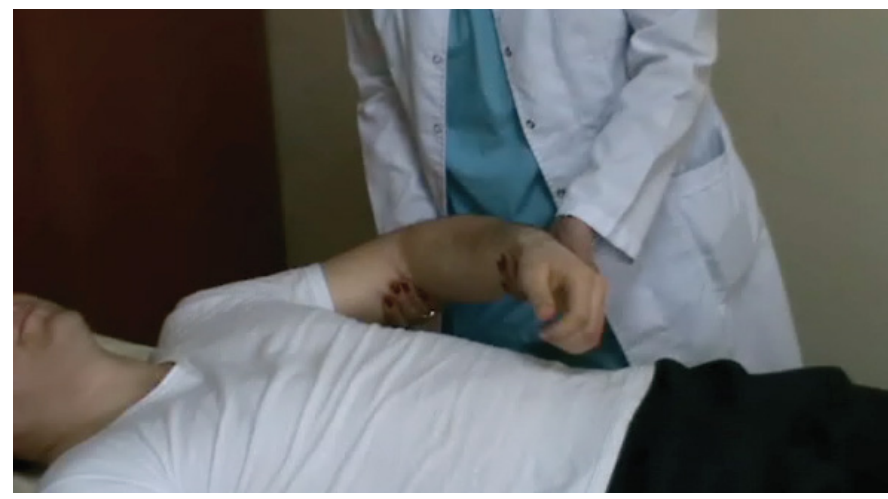

Figure 3. Evaluation position of muscle strength grades 2, 1, and $0 / 5$ in elbow flexion

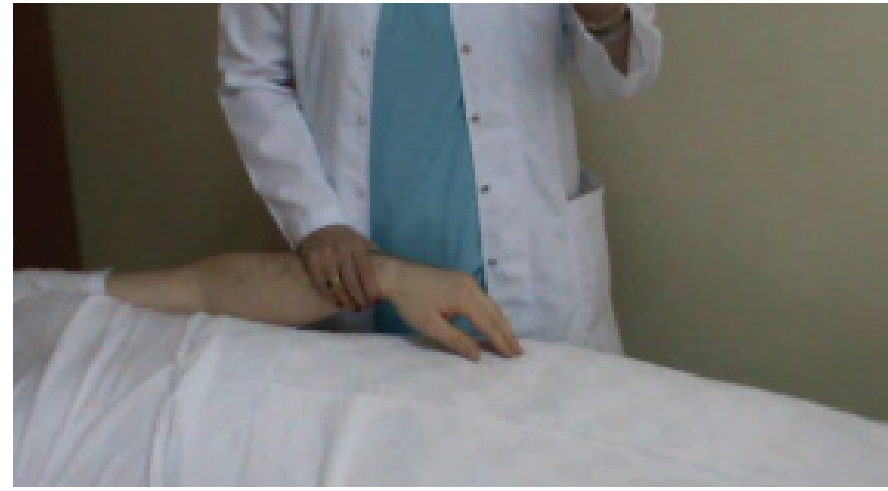

Figure 4. Evaluation position of muscle strength grade $3 / 5$ in the wrist extensors 


\section{C7 Elbow Extensors-Triceps}

Muscle strength grade $3 / 5$

The upper arm is supported when the shoulder is in neutral rotation, adduction, and $90^{\circ}$ of flexion and the elbow is in full extension with the palm of the hand resting by the ear. The patient is instructed to "straighten your arm". The patient attempts to complete the range of elbow extension against gravity. If the motion is completed, the grade of muscle strength is 3/5 (Figure 7).

\section{Muscle strength grades $4 / 5$ and 5/5}

The position of the upper extremity is the same as in the grade of $3 / 5$, except that the elbow is in $45^{\circ}$ of flexion. The upper arm is supported, the wrist is grasped, and force is applied to the distal forearm in the direction of elbow flexion. The patient is instructed to "don't let me bend your elbow, hold your position". The patient resists by attempting to maintain the position of the elbow in $45^{\circ}$ of flexion. If the patient shows full resistance to the force, the grade of muscle strength is $5 / 5$. In the case of partial resistance, the grade of muscle strength is 4/5 (Figure 8).

\section{Muscle strength grade $2 / 5$}

While assessing the muscle strength grade of $2 / 5$, sufficient flexion of the shoulder must be permitted for the forearm to move easily over the chest and abdomen. The patient's arm is supported when the shoulder is in internal rotation and adduction, the elbow is fully flexed, and the forearm is in neutral supination/pronation. The patient is instructed to "straighten your arm". If the patient completes elbow extension through the full range of motion, the grade of muscle strength is $2 / 5$ (Figure 9).

\section{Muscle strength grades $0 / 5$ and $1 / 5$}

While evaluating the muscle strength of $0 / 5$ or $1 / 5$, the elbow is kept in $30^{\circ}$ of flexion and the arm is supported. The patient is instructed to "try to straighten your arm". To determine trace function in the triceps during full extension, palpation is performed at its insertion on the olecranon or the belly. If movement is felt or observed, the grade of muscle strength is $1 / 5$. If not, the muscle strength is $0 / 5$ (Figure 10).

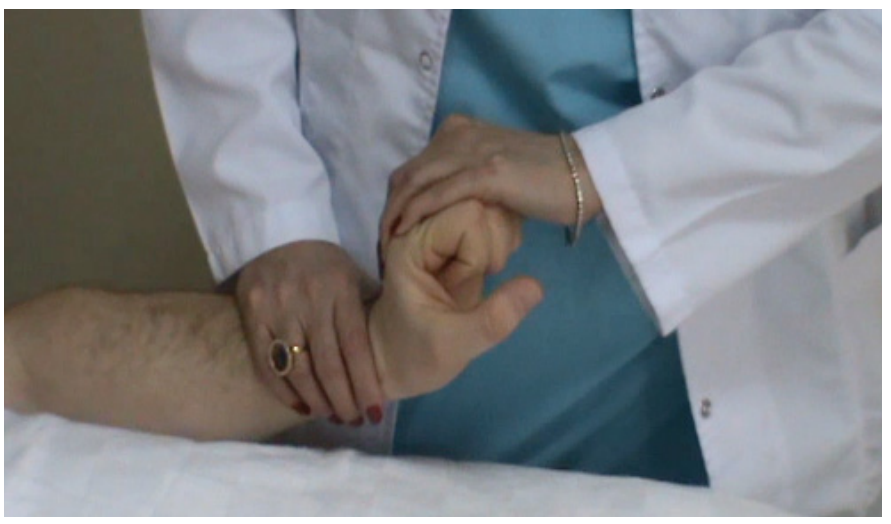

Figure 5. Evaluation position of muscle strength grades $4 / 5$ and $5 / 5$ in the wrist extensors
Note: External rotation movement, which occurs in the shoulder by quickly flexing the elbow and then relaxing, can mimic elbow extension. To prevent this, it is important to position the patient properly and to palpate the correct muscle.

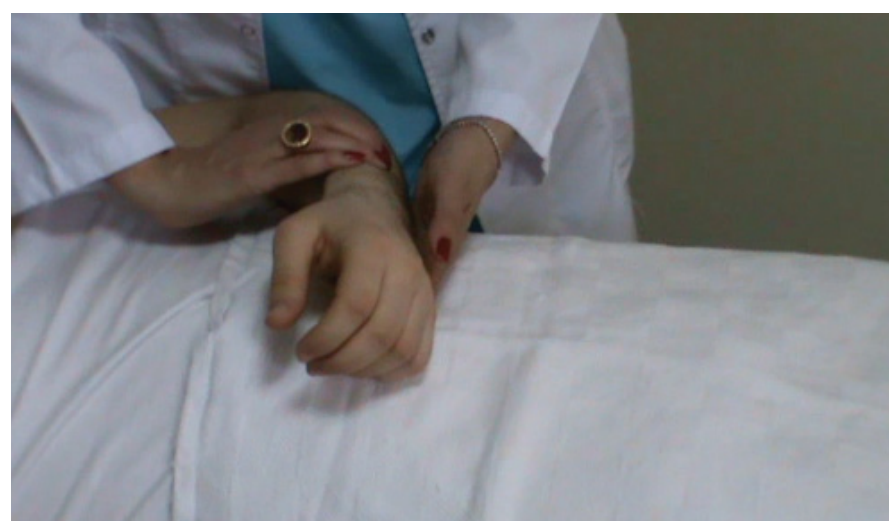

Figure 6. Evaluation position of muscle strength grades $0 / 5$, $1 / 5$, and $2 / 5$ in the wrist extensors

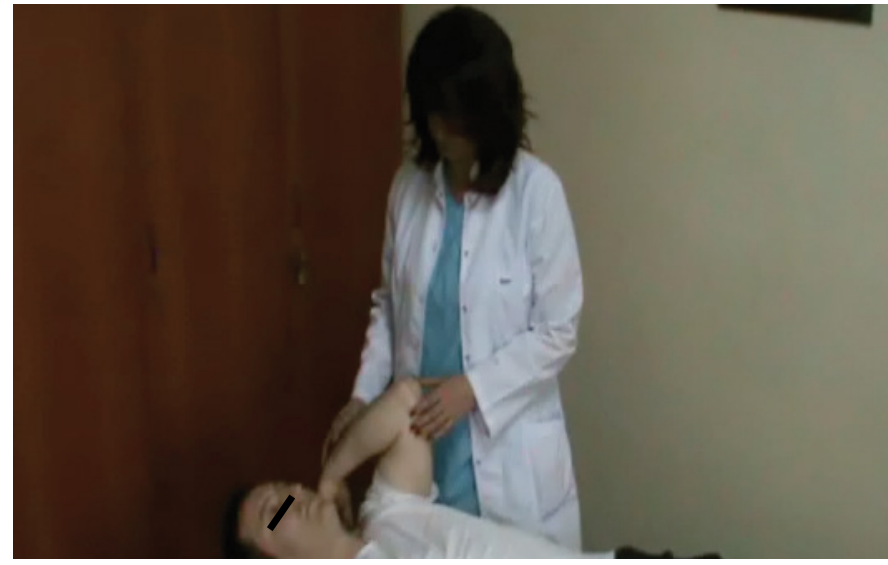

Figure 7. Evaluation position of muscle strength grade $3 / 5$ in the elbow extensors

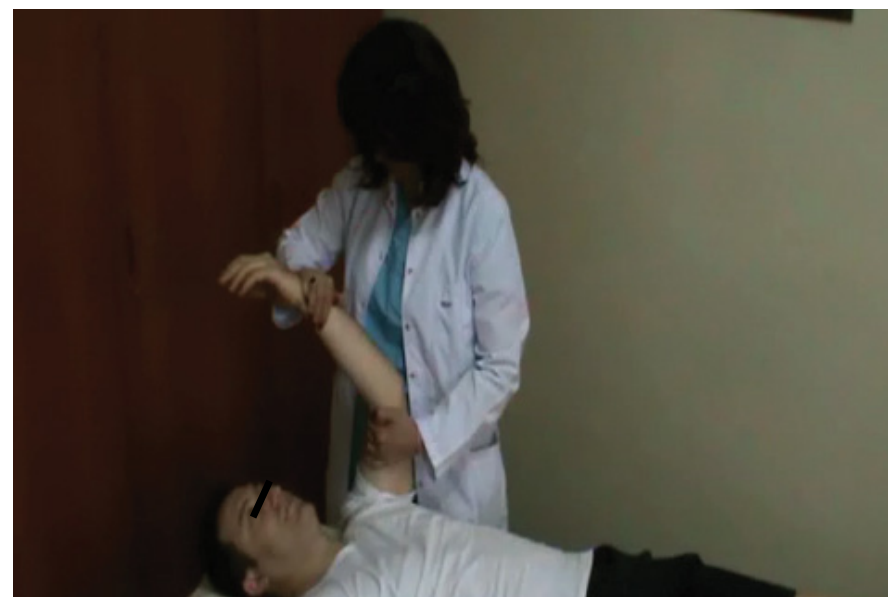

Figure 8 . Evaluation position of muscle strength grades $4 / 5$ and $5 / 5$ in the elbow extensors 


\section{C8 Long Finger Flexors-Flexor Digitorum Profundus}

\section{Muscle strength grade $3 / 5$}

The metacarpal phalangeal (MCP) and proximal interphalangeal joints (PIP) in the middle finger of the hand to be evaluated are stabilized in extension when the shoulder is in neutral rotation, flexion/extension, and adduction, the elbow is in full extension, the forearm is in full supination, and the wrist is in neutral flexion/extension (stabilization is performed with one or two hands). The thumb of the examiner supports the volar aspect of the $3^{\text {rd }}$ middle phalanx. The patient is instructed to "bend the tip of your middle finger". The patient attempts to bring the distal interphalangeal (DIP) joint of the middle finger into full flexion. If the patient can perform the movement through the full range of motion, the grade of muscle strength is $3 / 5$ (Figure 11).

\section{Muscle strength grades 4/5 and 5/5}

The wrist, MCP, and PIP joints are stabilized when the DIP joint of the middle finger is fully flexed and the other joints are in the same position as in grade $3 / 5$. While force is applied to the DIP joint of the $3^{\text {rd }}$ finger in the direction of extension, the patient is given the instruction to "hold the tip of your middle finger in this bent position, resist me." If the patient fully resists the force, the grade of muscle strength is $5 / 5$. If the patient resists partially, the muscle strength is $4 / 5$ (Figure 12).

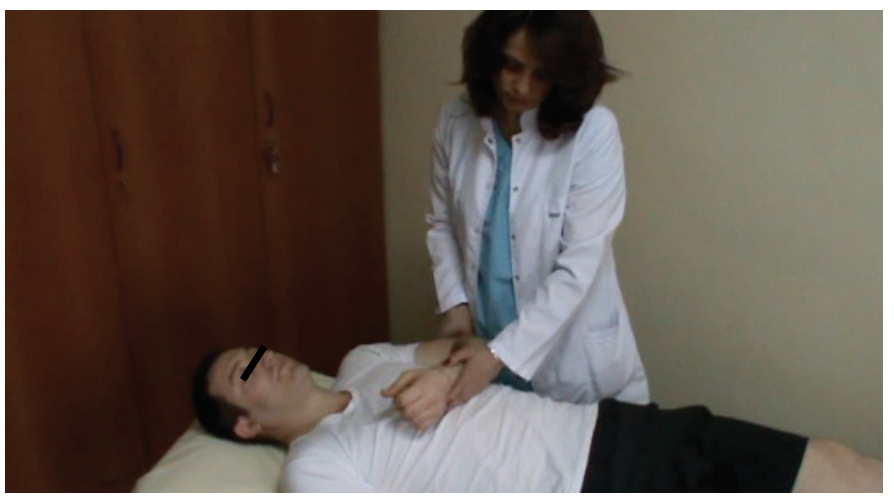

Figure 9. Evaluation position of muscle strength grade $2 / 5$ in the elbow extensors

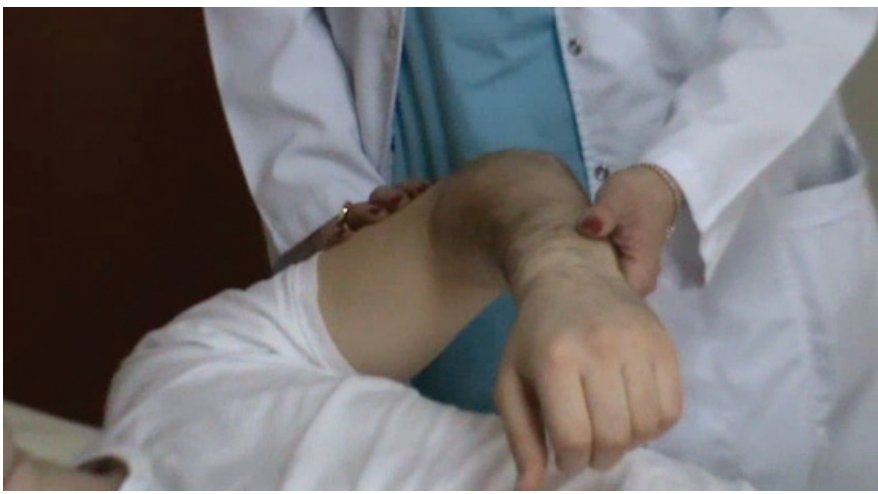

Figure 10. Evaluation position of muscle strength grades 1 and $0 / 5$ in the elbow extensors

\section{Muscle strength grades $0 / 5,1 / 5$, and $2 / 5$}

The MCP and PIP joints of the hand to be evaluated are stabilized in extension and the wrist is stabilized in neutral position when the shoulder is in neutral rotation, flexion/extension, and adduction, the elbow is in full extension, the forearm is in neutral pronation/supination, and the wrist is in neutral flexion/extension. The patient is given the instruction to "try to bend the tip of your middle finger". In the presence of a movement palpated in the tendons of the long finger flexors or observed in the muscle belly while the patient is trying to perform the movement, the grade of muscle strength is $1 / 5$. If there is no movement, the grade of muscle strength is $0 / 5$ (Figure 13). Note: While testing the grades $1 / 5$ through $3 / 5$, if the wrist stabilization is incorrect, involuntary flexion movement is seen in the distal phalanx due to the tenodesis effect. This situation could be misinterpreted as voluntary contraction of the long finger flexors. Moreover, while testing the grades $4 / 5$ and $5 / 5$, if the stabilization of the proximal phalanges is incorrect, the contraction of the intrinsic

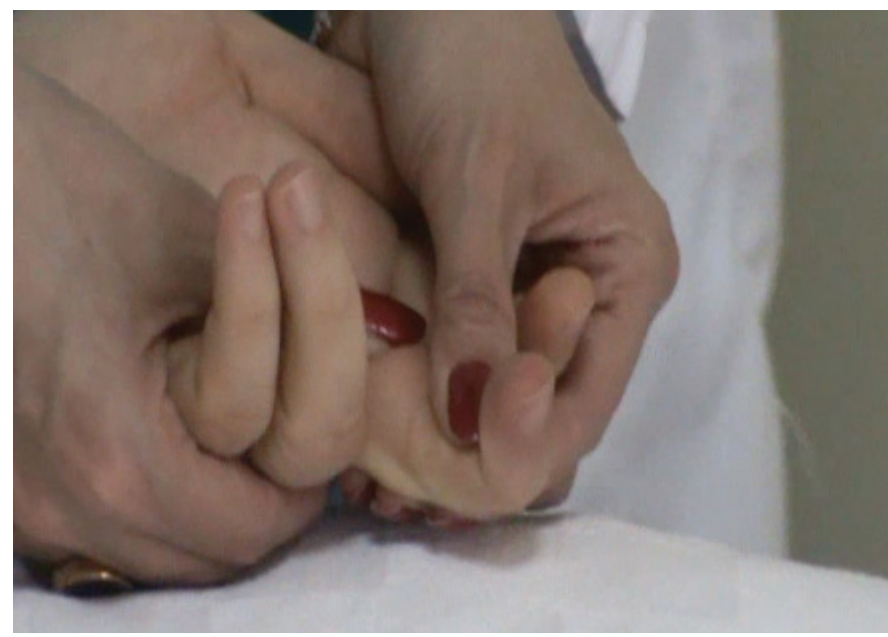

Figure 11. Evaluation position of muscle strength grade $3 / 5$ in the long finger flexors

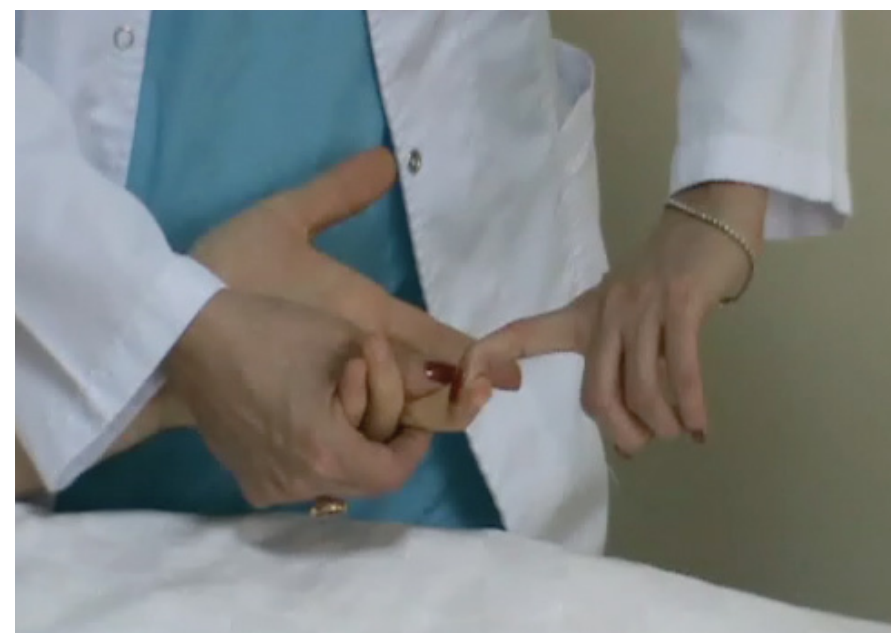

Figure 12. Evaluation position of muscle strength grades $4 / 5$ and $5 / 5$ in the long finger flexors 
muscles and flexor digitorum superficialis could be misinterpreted as if there was movement in the DIP joints.

\section{T1 Small Finger Abductor-Abductor Digiti Minimi}

\section{Muscle strength grade $3 / 5$}

The patient's hand is stabilized and supported assuring the prevention of hyperextension of the MCP joints when the shoulder is in internal rotation, adduction, and $15^{\circ}$ of flexion; the elbow is in $90^{\circ}$ of flexion; the forearm is in pronation; and the wrist is in neutral extension/flexion. The patient is instructed to "move your little finger away from your ring finger". If the patient can move the little finger through the full range of motion in abduction, the grade of muscle strength is $3 / 5$ (Figure 14).

\section{Muscle strength grades $4 / 5$ and $5 / 5$}

The positions of the joints are the same as those in grade $3 / 5$, except that the little finger is in full abduction. Again, the hand is stabilized and supported assuring the prevention of hyperextension of the MCP joints. The patient is given the instruction to "hold your little finger away from your ring finger and resist my pushing". Pressure is applied by the index finger of the examiner against the side of the patient's distal phalanx. If the patient displays full resistance to the force, the grade of muscle strength is $5 / 5$, whereas if the patient displays partial resistance, the grade of muscle strength is $4 / 5$ (Figure 15).

\section{Muscle strength grades $0 / 5,1 / 5$, and $2 / 5$}

The MCP joints are stabilized when the shoulder is in neutral rotation, neutral flexion/extension, and adduction; the elbow is in full extension; the forearm is in full pronation; and the wrist
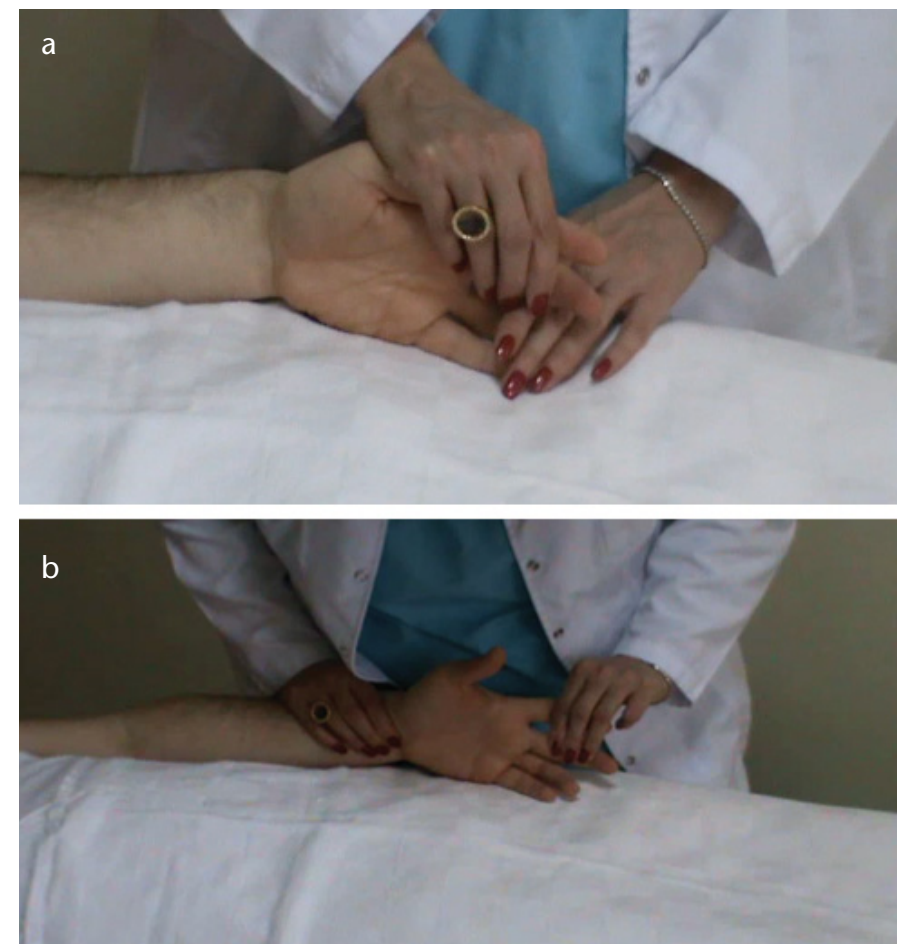

Figure 13. a, b. Evaluation position of muscle strength grades $2 / 5$ (a) and $0 / 5$ and $1 / 5$ (b) in the long finger flexors is in neutral flexion/extension (as an alternative to this position, the MCP joints can be stabilized when the shoulder is in internal rotation, adduction, and neutral flexion/extension; the elbow is in $90^{\circ}$ of flexion; and the forearm and wrist are in neutral flexion/extension).

The hyperextension of MCPs is prevented by applying light pressure to the dorsal aspect of the hand and wrist. The patient is instructed to "move your little finger away from your ring finger". If the patient completes the full range of motion, the grade of muscle strength is $2 / 5$ (Figure 16). If there is a contraction that is palpated in the abductor digiti minimi muscle or observed in the muscle belly during the movement, the grade of muscle strength is $1 / 5$. In the absence of any movement, the grade of muscle strength is $0 / 5$ (Figure 17).

Note: Finger extension can sometimes be misinterpreted as abduction in the $5^{\text {th }}$ finger. Proper positioning and stabilization are important to prevent this misinterpretation.

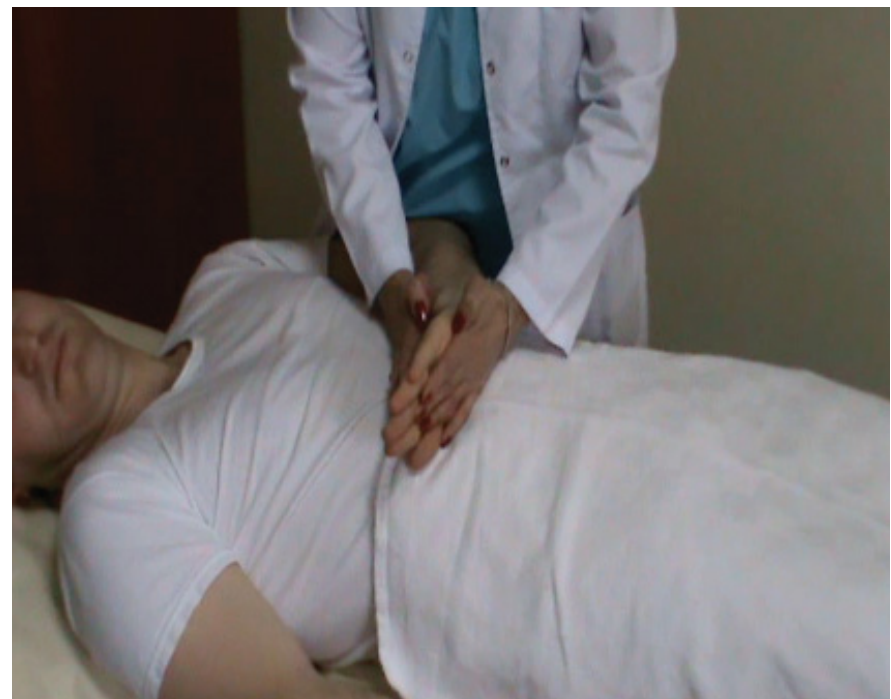

Figure 14. Evaluation position of muscle strength grade $3 / 5$ in the small finger abductor

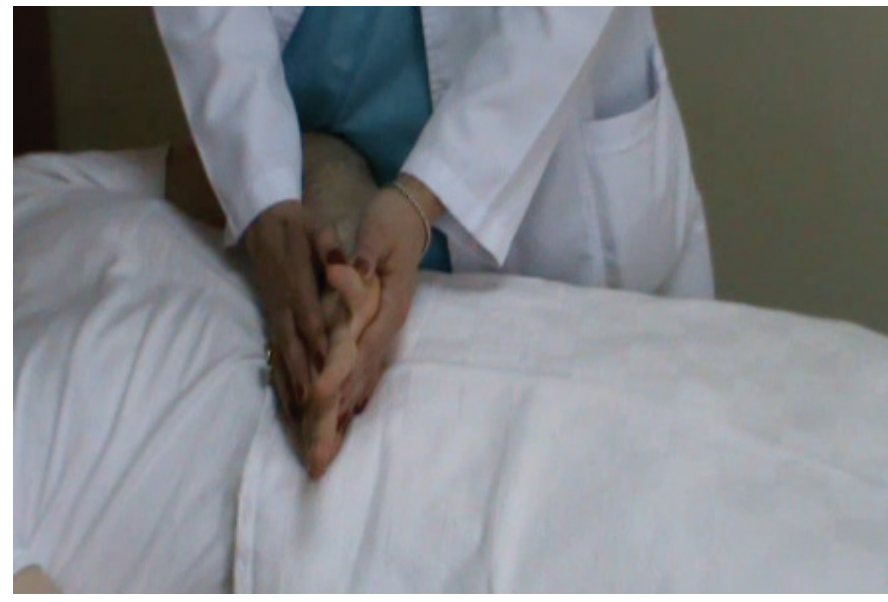

Figure 15. Evaluation position of muscle strength grades $4 / 5$ and $5 / 5$ in the small finger abductor 


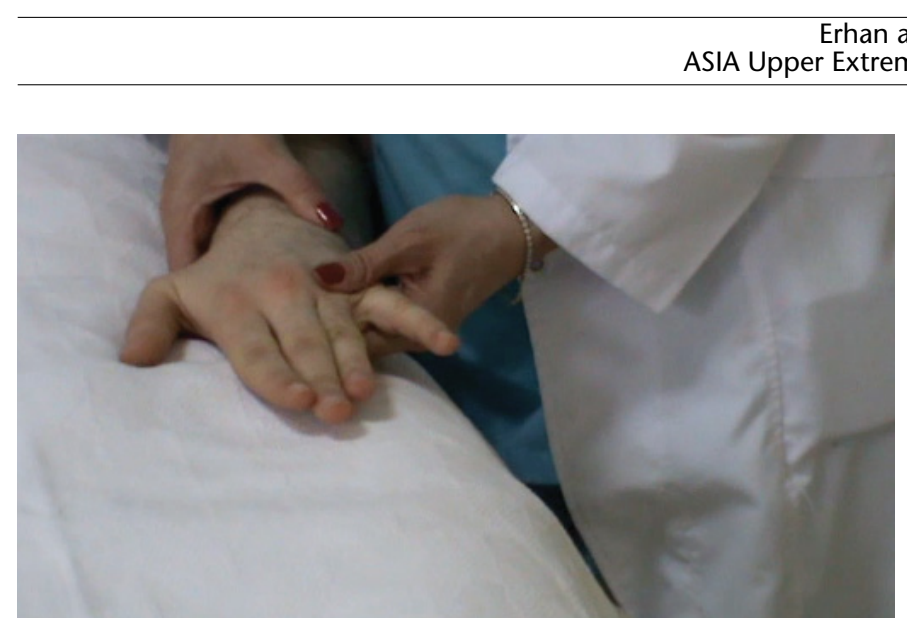

Figure 16. Evaluation position of muscle strength grades $4 / 5$ and $5 / 5$ in the small finger abductor

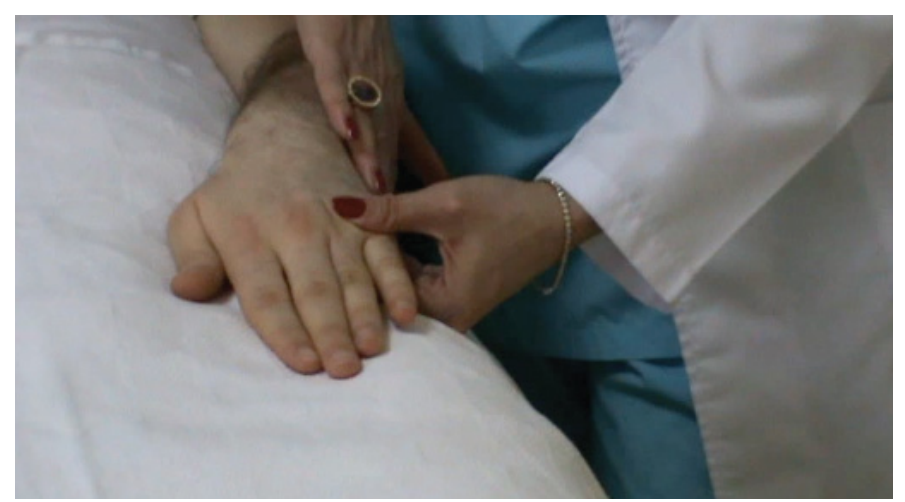

Figure 17. Evaluation position of muscle strength grades $0 / 5$ and $1 / 5$ in the small finger abductor

Peer-review: This manuscript was prepared by the invitation of the Editorial Board and its scientific evaluation was carried out by the Editorial Board.

Author Contributions: Concept - B.E.; Design - B.E.; Supervision -B.E.; Resource - B.E.; Materials - B.E.; Data Collection and/or Processing - B.E.;
Analysis and/or Interpretation - B.E.; Literature Review - B.E., B.G.; Writer - B.E.; Critical Review - B.G.; Other - B.E.

Acknowledgment: We would like to thank Ufuk Karanfil and Dr. Alkan Öztürk for the motor examination photos.

Conflict of Interest: No conflict of interest was declared by the authors.

Financial Disclosure: The authors declared that this study has received no financial support.

\section{References}

1. Erhan $B$, Gündüz B. Omurilik yaralanmalı hastanın rehabilitasyonu. In: Zileli M, Özer AF, editörler. Omurilik ve Omurga Cerrahisi (3. Basım). Inter Tıp Yayınevi, İzmir, 2014. p.1879-89.

2. Kirshblum S, Donovan WH. Neurologic assessment and classification of traumatic spinal cord injury. In: Kirshblum S, Campagnolo DI, DeLisa JA, editors. Spinal Cord Medicine, Philadelphia: Lippincott Williams Wilkins; 2002. p.82-95.

3. American Spinal Injury Association: International Standards for Neurological Classification of Spinal Cord Injury, revised 2011; Atlanta GA.

4. Kirshblum SC, Waring W, Biering-Sorensen F, Burns SP, Johansen M, Schmidt-Read M, et al. Reference for the 2011 revision of the International Standards for Neurological Classification of Spinal Cord Injury. J Spinal Cord Med 2011;34:547-54. [CrossRef]

5. Gündüz B, Erhan B. Omurilik Yaralanması Nörolojik Sınıflaması için Uluslararası Standartlar 2011 Revizyonu: Değerlendirme Formu Türkçe Çevirisi. Turk J Phys Med Rehab 2012;58 (Özel Sayı 1):42-5.

6. Gündüz B, Erhan B. Omurilik Yaralanması Nörolojik Sınıflaması için Standartlar Değerlendirme Formunun Güncellenmesi. Turk J Phys Med Rehab 2015;61:91-4.

7. Gündüz B, Erhan B. Omurga-omurilik yaralanmalarında klinik muayene ve sınıflama. In: Hancı M, Erhan B, editörler: Omurga ve Omurilik Yaralanmaları. İmir, Inter Tıp Yayınevi. 2012. p.207-20.

8. InSTeP. Avalaible from: http://content.learnshare.com/courses/120/393989/player.html. Dec 1, 2014.

9. InSTeP. Avalaible from: www.asialearningcenter.com. Dec 4th, 2014. 